\title{
Pharmacological reversal of endothelin-I mediated constriction of the spiral modiolar artery: a potential new treatment for sudden sensorineural hearing loss
} Elias Q Scherer*1,2, Wolfgang Arnold ${ }^{2}$ and Philine Wangemann ${ }^{1}$

\author{
Address: ${ }^{1}$ Cell Physiology Laboratory, Dept. Anatomy \& Physiology, Kansas State University, Manhattan, KS 66506, USA and ${ }^{2}$ Department of \\ Otorhinolaryngology, Head and Neck Surgery, Technical University of Munich, Klinikum rechts der Isar, Ismaninger Str. 22, 81675 Munich, \\ Germany \\ Email: Elias Q Scherer* - e.q.scherer@lrz.tum.de; Wolfgang Arnold -w.arnold@lrz.tum.de; Philine Wangemann - wange@vet.ksu.edu \\ * Corresponding author
}

Published: 29 November 2005

BMC Ear, Nose and Throat Disorders 2005, 5:10 doi:10.1186/1472-6815-5-10

This article is available from: http://www.biomedcentral.com/I472-68/5/5/10

(c) 2005 Scherer et al; licensee BioMed Central Ltd.

This is an Open Access article distributed under the terms of the Creative Commons Attribution License (http://creativecommons.org/licenses/by/2.0), which permits unrestricted use, distribution, and reproduction in any medium, provided the original work is properly cited.
Received: 16 June 2005
Accepted: 29 November 2005

\begin{abstract}
Background: Vasospasm of the spiral modiolar artery (SMA) may cause ischemic stroke of the inner ear. Endothelin-I (ET-I) induces a strong, long-lasting constriction of the SMA by increasing contractile apparatus $\mathrm{Ca}^{2+}$ sensitivity via Rho-kinase. We therefore tested several Rho-kinase inhibitors and a cell-permeable analogue of cAMP (dbcAMP) for their ability to reverse ET-Iinduced constriction and $\mathrm{Ca}^{2+}$-sensitization.
\end{abstract}

Methods: The present study employed SMA isolated from gerbil temporal bones. $\mathrm{Ca}^{2+}$ sensitivity was evaluated by correlating vascular diameter and smooth muscle cell $\left[\mathrm{Ca}^{2+}\right]_{\mathrm{i}}$, measured by fluo4-microfluorometry and videomicroscopy.

Results: The Rho-kinase inhibitors Y-27632, fasudil, and hydroxy-fasudil reversed ET-I-induced vasoconstriction with an $I C_{50}$ of 3,15 , and III $\mu \mathrm{mol} / \mathrm{L}$, respectively. DbcAMP stimulated a dosedependent vasodilation $\left(E C_{50}=1 \mathrm{mmol} / \mathrm{L}\right)$ and a reduction of $\left[\mathrm{Ca}^{2+}\right]_{\mathrm{i}}\left(E C_{50}=0.3 \mu \mathrm{mol} / \mathrm{L}\right)$ of $\mathrm{ET}-\mathrm{I}$ preconstricted vessels ( $\mathrm{I} \mathrm{nmol} / \mathrm{L})$. Fasudil and dbcAMP both reversed the $E T$ - I-induced increase in $\mathrm{Ca}^{2+}$ sensitivity.

Conclusion: Rho-kinase inhibition and dbcAMP reversed ET-I-induced vasoconstriction and $\mathrm{Ca}^{2+}$-sensitization. Therefore, Rho-kinase inhibitors or cAMP modulators could possess promise as pharmacological tools for the treatment of ET-I-induced constriction, ischemic stroke and sudden hearing loss.

\section{Background}

The inner ear's blood supply depends solely on the spiral modiolar artery (SMA), a functional end artery. Vasospasm/constriction of the SMA can cause an ischemic stroke of the inner ear, leading to sudden sensorineural hearing loss (SSHL). Thus, investigating the mechanisms controlling the inner ear microcirculation is a prerequisite for the development of new strategies to treat SSHL.

Capillary blood flow is primarily regulated by the resistance of precapillary arteries. The vascular resistance is a function of the contractile status of the vascular smooth muscle cells (VSMCs). Constriction of VSMCs results from 
an increase in intracellular $\mathrm{Ca}^{2+}\left(\left[\mathrm{Ca}^{2+}\right]_{\mathrm{i}}\right)$ and/or by an increase in the $\mathrm{Ca}^{2+}$ sensitivity of the contractile apparatus $[1,2]$. One key mechanism enhancing $\mathrm{Ca}^{2+}$ sensitivity and thus vascular tone is Rho-kinase signalling, which results in inhibition of myosin light chain phosphatase $[2,3]$. Rho-kinase activation has been shown to cause vasospasm of coronary, cerebral and spiral modiolar arteries [49].

One of the strongest Rho-kinase activators described so far is the vasoconstrictor endothelin-1 (ET-1). The synthesis of ET-1 by endothelial cells is activated by physiological stimuli such as shear stress, insulin, thrombin and other vascular factors [10]. ET-1 and $\mathrm{ET}_{\mathrm{A}}$ receptors play a fundamental role in the maintenance of basal vasomotor tone in resistance arteries [11]. The synthesis of ET-1 can be increased by hypoxia and elevated oxidized low-density lipoproteins $[12,13]$ and has been implicated in the pathogenesis of a number of cerebrovascular disorders, including stroke, ischemia, and, in particular, cerebral vasospasm $[14,15]$. Thus, ET-1 possesses pathological potential in addition to its physiological functions. ET- 1 is present in the SMA and induces strong, long-lasting constriction via $\mathrm{ET}_{\mathrm{A}}$-receptor-mediated Rho-kinase activation $[9,16,17]$. Taken together ET-1 is likely an endogenous regulator of inner ear microvascular tone.

We have previously shown that CGRP is able to reverse ET-1-induced constrictions in the SMA via an increase in vascular smooth muscle cAMP [18]. CGRP is present in perivascular nerves of the SMA and therefore is a potential endogenous vasodilator of the SMA. We propose, therefore, that reversal of ET-1-induced constriction is not necessarily limited to inhibition of ET-1-related mechanisms (e.g., Rho-kinase signalling).

These findings provide a clinical perspective for a new treatment of SSHL, because both Rho-kinase signalling and CAMP can be targeted via pharmacological agents. Therefore, we assessed the potency of clinically relevant Rho-kinase inhibitors and a cell-permeable analogue cAMP (dbcAMP) in terms of reversing ET-1-induced constriction and $\mathrm{Ca}^{2+}$-sensitization in the SMA.

\section{Methods}

\section{Drugs and solutions}

The physiologic salt solution (PSS) contained (in mmol/ L) $150 \mathrm{NaCl}, 3.6 \mathrm{KCl}, 1.0 \mathrm{MgCl}_{2}, 1.0 \mathrm{CaCl}_{2}, 5.0$ HEPES, and 5.0 glucose, $\mathrm{pH}$ 7.4. Extracellular $\mathrm{Ca}^{2+}$ concentration $\left(\left[\mathrm{Ca}^{2+}\right]_{\mathrm{ex}}\right)$ was raised to 3 and $10 \mathrm{mmol} / \mathrm{L}$ by addition of $\mathrm{CaCl}_{2}$. A maximal vasodilation was induced by the removal of extracellular $\mathrm{Ca}^{2+}$. The nominally $\mathrm{Ca}^{2+}$-free solution contained (in mmol/L) $150 \mathrm{NaCl}, 3.6 \mathrm{KC} 1,1.0$ $\mathrm{MgCl}_{2}$, 1.0 EGTA, 5.0 HEPES, and 5.0 glucose, $\mathrm{pH}=7.4$. Fluo-4-AM (Molecular Probes) was dissolved in anhy- drous DMSO and stored in $1 \mathrm{mmol} / \mathrm{L}$ aliquots. Y-27632 was kindly provided by Welfide. Fasudil was obtained from Calbiochem. Fasudil (obtained from Tocris Cookson) was modified to hydroxyfasudil by Dr. Duy Hua, Dept of Chemistry, Kansas State University. All other chemicals were obtained from Sigma.

\section{Preparation of the spiral modiolar artery (SMA)}

Experiments were conducted on tissues isolated from gerbils under a protocol that was approved by the Institutional Animal Care and Use Committee at Kansas State University. Gerbils were anesthetized with sodium pentobarbital $(100 \mathrm{mg} / \mathrm{kg}$ i.p.) and decapitated. Temporal bones were removed, opened and placed into a micro-dissection chamber containing PSS at $4{ }^{\circ} \mathrm{C}$. The SMA was isolated from the cochlea by micro-dissection as described previously [19]. Briefly, the cochlea was opened. The bone surrounding the modiolus was carefully removed and the SMA, which is only loosely attached to the eighth cranial nerve, was isolated. Care was taken to not stretch the artery.

\section{Simultaneous measurement of vascular diameter and $\left[\mathrm{Ca}^{2+}\right]_{i}$}

The simultaneous measurement of vascular diameter and $\left[\mathrm{Ca}^{2+}\right]_{i}$ has been described previously [17]. Briefly, the smooth muscle cells of vessel segments were loaded with the $\mathrm{Ca}^{2+}$ indicator dye fluo- 4 by incubation in PSS containing $5 \mu \mathrm{mol} / \mathrm{L}$ fluo-4-AM for $35 \mathrm{~min}$ at $37^{\circ} \mathrm{C}$. After loading, vessel segments were washed with PSS and maintained at $4^{\circ} \mathrm{C}$ for 20 minutes prior to experimentation at $37^{\circ} \mathrm{C}$. Vessel segments were transferred into a bath chamber mounted on the stage of an inverted microscope (Nikon). Fluorescence emitted by fluo-4 (518-542 nm) in response to excitation at $488 \mathrm{~nm}$ (Photon Technology International) was detected by a photon counter (Photon Technology International). For measurements of the vascular diameter, the vessel was illuminated at $605-615 \mathrm{~nm}$ and the transmission image was recorded with a chilled CCD camera (Hamamatsu). The outer vascular diameter was measured by two video edge detectors (Crescent). Fluorescence and calibrated diameter signals were digitized and recorded simultaneously (Photon Technology International).

\section{Experimental protocols}

Experiments were started $20 \mathrm{~min}$ after loading with fluo4. Vessel segments were superfused at a rate of $9 \mathrm{ml} / \mathrm{min}$ with PSS. This flow rate corresponds to an exchange rate of 2 bath chambers volumes/sec, given the bath chamber volume of $75 \mu \mathrm{l}$. Upon start of the superfusion, the unpressurized artery develops a spontaneous vascular tone that is sensitive to removal of extracellular $\mathrm{Ca}^{2+}$ and inhibition of L-type $\mathrm{Ca}^{2+}$ channels with nanomolar concentrations of nifedipine [19]. The viability of each vessel 

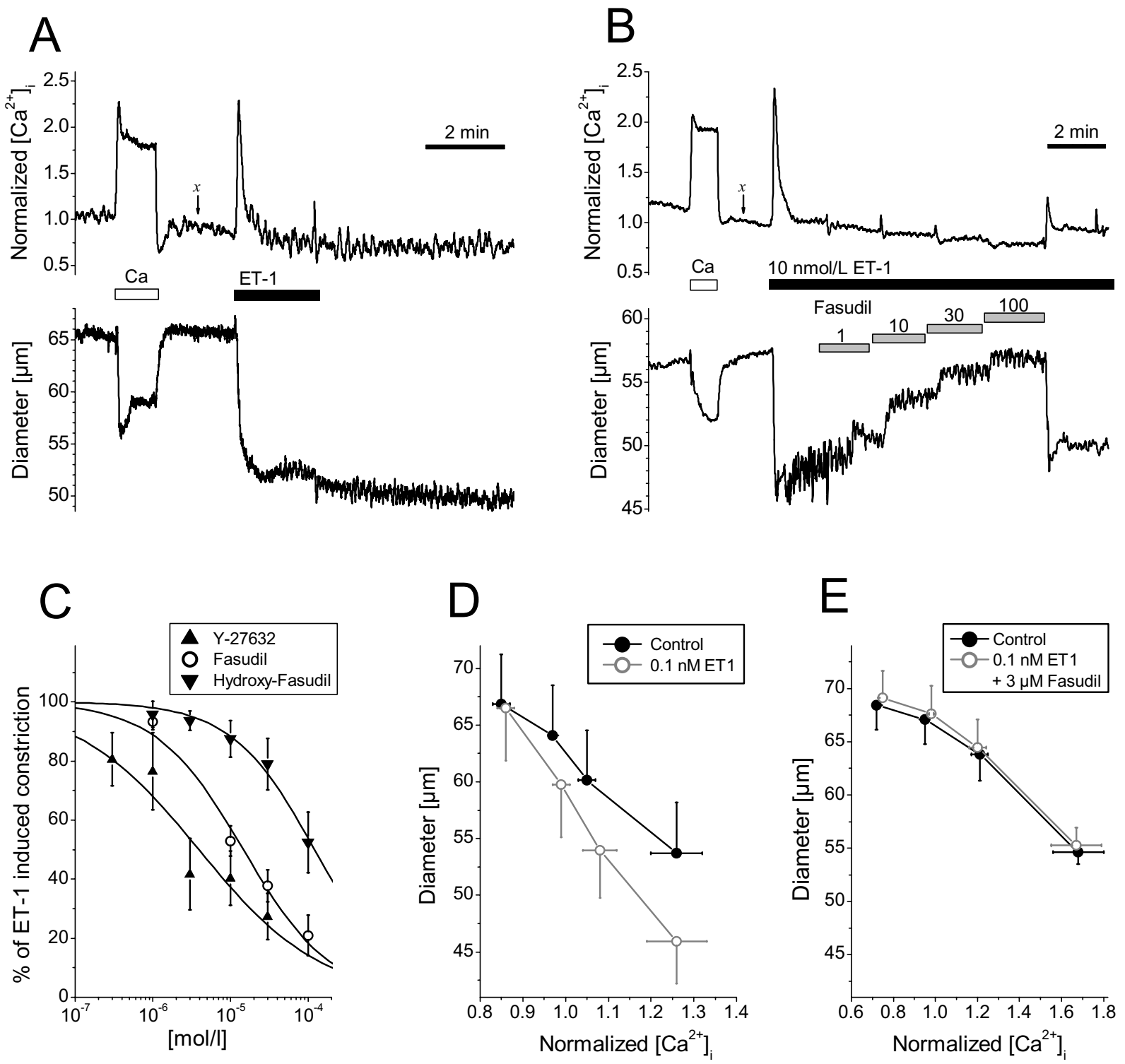

Figure I

Rho-kinase inhibitors reverse ET-I-induced constriction. A) Effect of $10 \mathrm{nmol} / \mathrm{L}$ endothelin-I (ET-I) on the cytosolic $\mathrm{Ca}^{2+}$ concentration $\left(\left[\mathrm{Ca}^{2+}\right]_{\mathrm{i}}\right)$ and the vascular diameter of the spiral modiolar artery. Note that ET-I caused a transient increase in $\left[\mathrm{Ca}^{2+}\right]_{i}$ and a sustained vasoconstriction and increase in vasomotion. This constriction outlasted the stimulation with ET-I. Increasing extracellular $\mathrm{Ca}^{2+}$ concentration $\left(\left[\mathrm{Ca}^{2+}\right]_{\mathrm{ex}}\right)$ to $10 \mathrm{mmol} / \mathrm{L}\left(" \mathrm{Ca}\right.$ ") induced an increase in $\left[\mathrm{Ca}^{2+}\right]_{\mathrm{i}}$ with parallel vasoconstriction. This increase of the $\left[\mathrm{Ca}^{2+}\right]_{\text {ex }}$ from I to $10 \mathrm{mmol} / \mathrm{L}$ ("Ca") served as a control experiment. Measurements of $\left[\mathrm{Ca}^{2+}\right]_{i}$ were normalized to the value obtained prior to the admission of ET-I (value at time ' $x$ ' was set to I). B) In the presence of $10 \mathrm{nmol} / \mathrm{L} \mathrm{ET}-\mathrm{I}$, increasing concentrations of fasudil $(\mathrm{I}-100 \mu \mathrm{mol} / \mathrm{L})$ induce dose-dependent relaxation. [Ca $\left.{ }^{2+}\right]_{\mathrm{i}}$ values were normalized, with the baseline value prior to application of ET-I designated as I.0 (denoted as " $x$ "). C) Dose-response curves for Y-27632-, fasudil- and hydroxy-fasudil-induced reversal of ET-I (I0 nmol/L) -mediated vasoconstriction. C) ET-I stimulated a significant increase in VSMC contractile apparatus $\mathrm{Ca}^{2+}$ sensitivity. D) Fasudil completely reversed the ET-I-induced Ca ${ }^{2+}$ sensitization. 
was assessed by its constrictor response to $10 \mathrm{mmol} / \mathrm{L}$ $\left[\mathrm{Ca}^{2+}\right]_{\mathrm{ex}}$. The $\left[\mathrm{Ca}^{2+}\right]_{\mathrm{i}}$ was monitored as fluorescence intensity and was normalized to the basal fluorescent emission prior to the beginning of each experiment. The fluorescence and diameter values taken for statistical analysis represent averages of the $\left[\mathrm{Ca}^{2+}\right]_{i}$-fluorescence and the vascular diameter over $30 \mathrm{sec}$ beginning $30 \mathrm{sec}$ after the onset of stimulation. We carefully validated the $\left[\mathrm{Ca}^{2+}\right]_{i}$-measurements with the non-ratiometric $\mathrm{Ca}^{2+}$-dye fluo- 4 by (i) excluding artefacts due to vessel diameter changes (evaluated by $\left[\mathrm{Ca}^{2+}\right]_{\text {ex }}$-versus ET-1 dose-response curves), (ii) excluding significant differences in the magnitude of $\left[\mathrm{Ca}^{2+}\right]_{i}$-changes between preparations, and (iii) assessing the same optimal dye-loading conditions in each experiment $[9,17]$.

Affinity constants $\left(\mathrm{K}_{\mathrm{DB}}\right)$ and concentrations that cause a half-maximal inhibition $\left(\mathrm{IC}_{50}\right)$ were determined in cumulative experiments and averaged after logarithmic transformation $\left(\mathrm{p} K_{D B}\right.$ and $\left.\mathrm{p} I C_{50}\right)$ as previously described [17].

The $\mathrm{Ca}^{2+}$ sensitivity of the contractile apparatus was determined by a correlation of $\left[\mathrm{Ca}^{2+}\right]_{i}$ and the vascular diameter as described previously [9]. Changes in $\left[\mathrm{Ca}^{2+}\right]_{\mathrm{i}}$ were induced by changes in $\left[\mathrm{Ca}^{2+}\right]_{\mathrm{ex}}$. Stepwise increases in $\left[\mathrm{Ca}^{2+}\right]_{\mathrm{ex}}$ from 0 to 1,3 and $10 \mathrm{mmol} / \mathrm{L}$ caused increases in $\left[\mathrm{Ca}^{2+}\right]_{\mathrm{i}}$ and decreases in the vascular diameter. Correlations were found to be linear $(r>0.95)$ within the measured range (the relation between calcium concentration and tension gets sigmoidal if the $\left[\mathrm{Ca}^{2+}\right]_{e x}$ and thus the $\left[\mathrm{Ca}^{2+}\right]_{\mathrm{i}}$ is further increased [9]). Slopes were quantified in the arbitrary unit $\mu \mathrm{m} / \mathrm{Ca}^{2+}$, where $\mu \mathrm{m}$ represent the change in the vascular diameter and $\mathrm{Ca}^{2+}$ represents the normalized change in the cytosolic $\mathrm{Ca}^{2+}$ concentration. Linear slopes were obtained to compare the $\mathrm{Ca}^{2+}$ sensitivity within paired experiments. In each vessel segment, the $\mathrm{Ca}^{2+}$ sensitivity was assessed under control and under experimental conditions.

Experiments of dbcAMP induced dilations were bracketed by $\mathrm{Ca}^{2+}$ free manoeuvres that were performed to induce a maximal vasodilation and reduce the $\left[\mathrm{Ca}^{2+}\right]_{\mathrm{i}}$ to a minimal level. Vascular diameter or fluorescence intensity in the absence of $\mathrm{Ca}^{2+}$ was considered as baseline. The magnitude of the vascular tone or fluorescence intensity was determined as the difference between the recorded value and the baseline value. Measurements were averaged over a period of $1 \mathrm{~min}$ to average vasomotion. DbcAMPinduced effects were normalized to the magnitude of the vascular tone or fluorescence intensity during $1 \mathrm{~min}$ immediately prior to the application of dbcAMP.

\section{Statistical analysis}

All results are expressed as average \pm SEM of $n$ experiments with $n$ representing the number of vessel segments. The significance of changes in the vascular diameter and of changes in the $\mathrm{Ca}^{2+}$ sensitivity were determined using Student's paired $t$-test. Differences were considered to be significant at error probabilities less than $0.05(P<0.05)$.

\section{Results}

This report is based on recordings of 50 vessels from 34 animals. The average vascular diameter was $65 \pm 1 \mu \mathrm{m}$.

\section{ET-I-induced constriction is reversed via Rho-kinase inhibitors}

ET-1 (10 nmol/L) induced a transient increase in $\left[\mathrm{Ca}^{2+}\right]_{\mathrm{i}}$, a strong and long-lasting vasoconstriction and a robust increase in the vasomotion of the gerbil spiral modiolar artery (Fig. 1A). The $\left[\mathrm{Ca}^{2+}\right]_{i}$ returned to almost resting levels after the transient increase, while the constriction was maintained. The ET-1-induced vasoconstriction was not readily reversible upon removal of ET-1 from the perfusate. The constriction and the increased vasomotion were observed without a significant change for at least 20 minutes after removal of ET-1 from the superfusate (data not shown). Note that ET-1-induced a transient $\left[\mathrm{Ca}^{2+}\right]_{i}$ increase and a sustained vasoconstriction while exposure to $10 \mathrm{mmol} / \mathrm{l} \mathrm{Ca}^{2+}$ induced an increase in $\left[\mathrm{Ca}^{2+}\right]_{\mathrm{i}}$ and $\mathrm{a}$ parallel vasoconstriction.

We tested the potency of different Rho-kinase inhibitors reversing ET-1-induced constriction. Figure 1B shows an original recording of an ET-1-induced constriction which is antagonized by increasing concentrations of fasudil. Fasudil mediated vasodilation were induced without significantly altering $\left[\mathrm{Ca}^{2+}\right]_{\mathrm{i}}$-levels. The Rho-kinase inhibitors Y-27632, fasudil and hydroxy-fasudil reversed ET-1induced constriction (10 nmol/L) in a dose-dependent manner (Figure 1C). The $1 C_{50}$ for Y-27632-, fasudil- and hydroxy-fasudil- mediated reversion of constriction was 3 $\mu \mathrm{mol} / \mathrm{L}\left(\mathrm{p} I C_{50}=5.50 \pm 0.31 ; \mathrm{n}=6\right), 15 \mu \mathrm{mol} / \mathrm{L}\left(\mathrm{p} I C_{50}=\right.$ $4.71 \pm 0.13 ; \mathrm{n}=7)$ and $111 \mu \mathrm{mol} / \mathrm{L}\left(\mathrm{p} I C_{50}=3.95 \pm 0.24 ;\right.$ $\mathrm{n}=6$ ), respectively. The $\mathrm{Ca}^{2+}$ sensitivity of the contractile apparatus was assessed as linear slopes obtained from correlations of $\left[\mathrm{Ca}^{2+}\right]_{i}$ and vascular diameter. ET-1 (100 $\mathrm{pmol} / \mathrm{L})$ increased the $\mathrm{Ca}^{2+}$ sensitivity $(-36 \pm 9$ versus -62 $\pm 13 \mu \mathrm{m} / \mathrm{Ca}^{2+}, \mathrm{n}=8$; Figure $\left.1 \mathrm{D}\right)$, fasudil $(3 \mu \mathrm{mol} / \mathrm{L})$ prevented the ET-1-induced increase in the $\mathrm{Ca}^{2+}$ sensitivity ($17 \pm 3$ versus $-16 \pm 2 \mu \mathrm{m} / \mathrm{Ca}^{2+}, \mathrm{n}=8$, Figure $\left.1 \mathrm{E}\right)$. Taken together, these observations demonstrate that ET-1induced constriction in the SMA is maintained by a Rhokinase-mediated increase of the $\mathrm{Ca}^{2+}$ sensitivity of the contractile apparatus, which can be effectively reversed by Rho-kinase inhibition.

\section{Exogenous, cell-permeable cAMP (dbcAMP) reverses ET- I-induced constriction and $\mathrm{Ca}^{2+}$ sensitization}

DbcAMP induced dose-dependant decreases in $\left[\mathrm{Ca}^{2+}\right]_{i}$ and reversal of constriction induced by $1 \mathrm{nmol} / \mathrm{L}$ ET- 1 

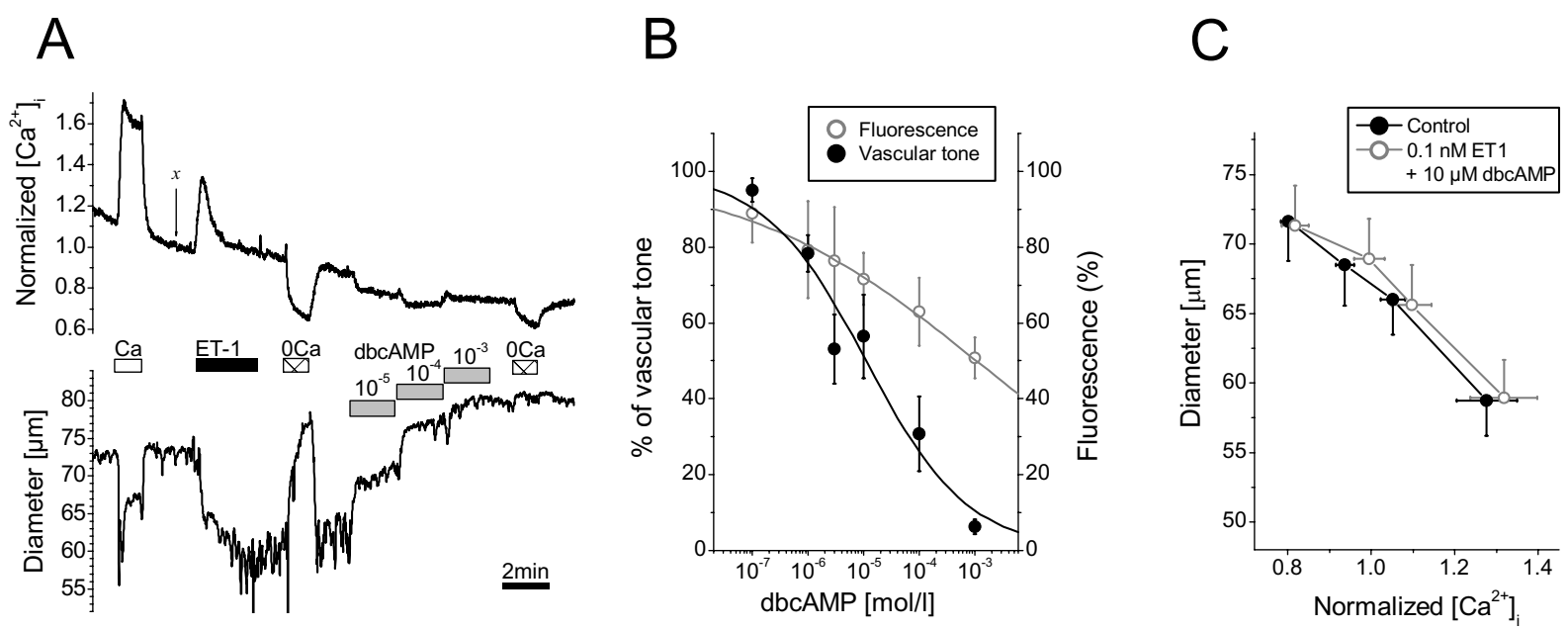

\section{Figure 2}

dbcAMP reverses ET-I ( $\mathrm{nmol} / \mathrm{L})$-induced vasoconstriction in a dose-dependent manner. A) A representative recording of $\left[\mathrm{Ca}^{2+}\right]_{\mathrm{i}}$-diameter measurements. The $\left[\mathrm{Ca}^{2+}\right]_{\mathrm{i}}$ was normalized to the value prior to application of ET-I (value at timepoint " $x$ " was set to I.0). Maximal vasodilation was determined by exposure of the SMA to Ca-free conditions ("0Ca"). An increase of extracellular $\mathrm{Ca}^{2+}$ to $10 \mathrm{mmol} / \mathrm{L}$ ("Ca") induced a $\left[\mathrm{Ca}^{2+}\right]_{i}$ increase and parallel vasoconstriction. B) Dose-response curves of dbcAMP-induced vasodilation and $\left[\mathrm{Ca}^{2+}\right]_{i}$ decrease of ET-I (I nmol/L) preconstricted SMA. C) dbcAMP prevented ET-I-induced $\mathrm{Ca}^{2+}$-sensitization.

with an $E C_{50}$ of $1 \mathrm{mmol} / \mathrm{L}$ and $0.3 \mu \mathrm{mol} / \mathrm{L}\left(\mathrm{pEC} C_{50}=2.97\right.$ \pm 0.09 and $6.49 \pm 0.07, \mathrm{n}=8$, Fig. $2 \mathrm{~A}$ and $2 \mathrm{~B}$ ), respectively. Note that dbcAMP-induced decreases in $\left[\mathrm{Ca}^{2+}\right]_{\mathrm{i}}$ were less pronounced than those induced by removal of $\mathrm{Ca}^{2+}$ from the extracellular solution although dilations were comparable (Fig. 2A). This observation suggests that the dilatory effect of cAMP is at least in part due to a decrease of the $\mathrm{Ca}^{2+}$ sensitivity of the contractile apparatus. Consistent with this interpretation is the apparent rightward shift of the dose-response curve of dbcAMP for change in $\left[\mathrm{Ca}^{2+}\right]_{i}$ (Fig. 2B). If CAMP and ET-1 have opposing effects on the $\mathrm{Ca}^{2+}$ sensitivity, it should be possible to prevent the ET-1induced increase in the $\mathrm{Ca}^{2+}$ sensitivity with dbcAMP. Indeed, $10 \mu \mathrm{mol} / \mathrm{L}$ dbcAMP prevented the increase in the $\mathrm{Ca}^{2+}$ sensitivity induced by $100 \mathrm{pmol} / \mathrm{L} \mathrm{ET}-1(-29 \pm 4$ versus $-27 \pm 3 \mu \mathrm{m} / \mathrm{Ca}^{2+}, \mathrm{n}=7$; Figure $2 \mathrm{C}$ ). These observations support the hypothesis that cAMP and Rho-kinase can interact as functional antagonists at the level of the $\mathrm{Ca}^{2+}$ sensitivity of the contractile apparatus.

\section{Discussion}

The primary observation of the present study is that the ET-1-induced SMA vasoconstriction is reversed by the Rho-kinase inhibitors Y-27632, fasudil and hydroxy-fasudil and by the cAMP analogue dbcAMP. All four agents decreased VSMC contractile apparatus $\mathrm{Ca}^{2+}$ sensitivity.
In general, ET-1-induced constriction has been found to be elicited by different $\mathrm{Ca}^{2+}$ mobilizing mechanisms, including $\mathrm{Ca}^{2+}$ release from intracellular $\mathrm{Ca}^{2+}$ stores via a phospholipase $\mathrm{C}$ mediated activation of $\mathrm{IP}_{3}$-receptors and activation of L-type and non-selective $\mathrm{Ca}^{2+}$ channels [2022]. $\mathrm{Ca}^{2+}$ mobilization has been considered to be the main mechanism of ET-1-induced constriction. In contrast, according to our previous results, ET-1-induced $\mathrm{Ca}^{2+}$ mobilization in the SMA appears to play a minor role [17]. The major mechanism of ET-1-induced constriction is an increase in the $\mathrm{Ca}^{2+}$ sensitivity of the contractile apparatus [9].

The increase in the $\mathrm{Ca}^{2+}$ sensitivity appears to be mediated by a Rho-kinase dependent inactivation of MLCP. This hypothesis is supported by two observations. First, inhibition of Rho-kinase with the selective Rho-kinase inhibitor Y-27632 abolished the ET-1-induced increase in the $\mathrm{Ca}^{2+}$ sensitivity. Y-27632 at concentrations of up to $10 \mu \mathrm{mol} / \mathrm{L}$ has been shown to be a selective Rho-kinase inhibitor [2325]. Second, inhibition of Rho-kinase with the selective Rho-kinase inhibitors fasudil and its functional metabolite hydroxy-fasudil also reversed ET-1-induced constriction and $\mathrm{Ca}^{2+}$ sensitization of the contractile apparatus. These inhibitors have also been shown to be selective Rho-kinase inhibitors up to $20 \mu \mathrm{mol} / \mathrm{L}[24,26,27]$. Since 
Y-27632 and the fasudil derivatives are structurally unique, but were observed to have similar functional effects, the concern of non-specific effects of the inhibitors can be minimized.

It has been shown that the Rho-kinase-dependent inhibition of the MLCP results from phosphorylation of the myosin-binding subunit (MBS) of the enzyme [28]. All Rho-kinase inhibitors employed in the present study reversed ET-1-induced constriction, with a clinically relevant $E C_{50}$ range below the level reported to cause systemic side effects (especially hypotension). This possibly indicates that basal Rho-kinase activity is rather low under normal conditions $[23,29]$. Thus, an up-regulation of Rho-kinase expression/activity under pathophysiological conditions (hypertension, cerebral and coronary vasospasm) would impart Rho-kinase inhibitors with pharmacological relevance [29].

We show that CAMP is a potent vasodilating second messenger in the SMA, acting by mechanisms which decrease $\left[\mathrm{Ca}^{2+}\right]_{i}$ and $\mathrm{Ca}^{2+}$ sensitivity. Although cAMP reduces intracellular $\mathrm{Ca}^{2+}$ levels, the present data demonstrate that the main pathway targets the $\mathrm{Ca}^{2+}$ sensitivity of the contractile apparatus. This interpretation is consistent with findings obtained in other preparations such as permeabilized intestinal and bronchial smooth muscle. In these studies the authors also could show that cAMP mediates a $\mathrm{Ca}^{2+}$ desensitization of the contractile apparatus [30,31]. cAMP seems to be the main second messenger of CGRP-induced $\mathrm{Ca}^{2+}$ desensitization and vasodilation in the SMA [18]. The data supports our hypothesis that the reversal of ET1-induced constriction is not limited to inhibition of ET1-related mechanisms (e.g., Rho-kinase signalling) and that ET-1-independent mechanisms can be targeted pharmacologically to reverse ET-1-mediated constriction. Clinical relevance arises from the possibility of modulating pharmacologically VSMC cAMP concentrations.

\section{Conclusion}

Although the sudden loss of hearing causes substantial distress and pronounced long-term effects in affected individuals, adequate strategies to clinically treat the disorder are lacking. One subgroup of SSHL is believed to arise from SMA vasospasm(s) which ultimately lead to ischemic stroke of the inner ear [32]. The targeting of two distinct signalling mechanisms, Rho-kinase and cAMP, were both effective in reversing SMA constriction. Of note, two of the agents employed in the present study (fasudil and hydroxy-fasudil) are currently used in the clinical setting and were found to be effective at concentrations below the threshold of systemic side effects [8,33]. Thus, this study presents two novel, clinically relevant approaches for the treatment of SSHL. We therefore pro- pose that clinical investigation into the use of these agents for SSHL treatment is warranted.

\section{Competing interests}

The author(s) declare that they have no competing interests.

\section{Authors' contributions}

EQS conducted all of the experiments and was involved in all aspects of data analysis and manuscript preparation. PW assisted with all facets of this study, assisting with data analysis and manuscript preparation. PW also provided laboratory space, equipment and financial support. WA provided financial support and made substantial contributions to conception and design of the present study.

All authors have been involved in drafting the manuscript and revising it critically for important intellectual content and given final approval of the version to be published.

\section{Acknowledgements}

The support by Research Grant ROI-DC04280 from the National Institute on Deafness and Other Communication Disorders, National Institutes of Health is gratefully acknowledged. The authors thank Dr. Steffen-Sebastian Bolz and Dr. Darcy Lidington for critically reviewing this manuscript and for giving important suggestions for improvement.

\section{References}

I. Hartshorne DJ: Biochemistry of the Contractile Process in Smooth Muscle. In Physiology of the Gastrointestinal Tract Edited by: Johnson LR. New York: Raven Press; 1987:423-482.

2. Somlyo AP, Somlyo AV: $\mathbf{C a}^{2+}$ Sensitivity of Smooth Muscle and Nonmuscle Myosin II: Modulated by G Proteins, Kinases, and Myosin Phosphatase. Physiol Rev 2003, 83: I 325-I358.

3. Kimura K, Ito M, Amano M, Chihara K, Fukata $Y$, Nakafuku M, Yamamori B, Feng J, Nakano T, Okawa K, Iwamatsu A, Kaibuchi K: Regulation of myosin phosphatase by Rho and Rho-associated kinase (Rho- kinase) [see comments]. Science I996, 273:245-248.

4. Sato M, Tani E, Fujikawa H, Kaibuchi K: Involvement of Rhokinase-mediated phosphorylation of myosin light chain in enhancement of cerebral vasospasm. Circ Res 2000, 87:195-200.

5. Fassbender K, Hodapp B, Rossol S, Bertsch T, Schmeck J, Schutt S, Fritzinger M, Horn P, Vajkoczy P, Wendel-Wellner M, Ragoschke A, Kuehl S, Brunner J, Schurer L, Schmiedeck P, Hennerici M: Endothelin-I in subarachnoid hemorrhage: An acute-phase reactant produced by cerebrospinal fluid leukocytes. Stroke 2000, 3 I :297 | -2975.

6. Kandabashi T, Shimokawa H, Miyata K, Kunihiro I, Kawano Y, Fukata Y, Higo T, Egashira K, Takahashi S, Kaibuchi K, Takeshita A: Inhibition of Myosin Phosphatase by Upregulated Rho-Kinase Plays a Key Role for Coronary Artery Spasm in a Porcine Model With Interleukin-I \{beta\}. Circulation 2000, 101:1319-1323.

7. Shimokawa H: Rho-kinase as a Novel Therapeutic Target in Treatment of Cardiovascular Diseases. J Cardiovasc Pharmacol 2002, 39:319-327.

8. Masumoto A, Mohri M, Shimokawa H, Urakami L, Usui M, Takeshita A: Suppression of Coronary Artery Spasm by the Rho-Kinase Inhibitor Fasudil in Patients With Vasospastic Angina. Circulation 2002, 105:1545-1547.

9. Scherer EQ, Herzog M, Wangemann P: Endothelin-I-Induced Vasospasms of Spiral Modiolar Artery Are Mediated by RhoKinase-Induced $\mathrm{Ca}^{2+}$ Sensitization of Contractile Apparatus and Reversed by Calcitonin Gene-Related Peptide. Stroke 2002, 33:2965-2971. 
10. Levin ER: Endothelins. N Engl J Med 1995, 333:356-363.

II. Haynes WG: Endothelins as regulators of vascular tone in man. Clin Sci (Colch) 1995, 88:509-517.

12. Rakugi H, Tabuchi Y, Nakamaru M, Nagano M, Higashimori K, Mikami $\mathrm{H}$, Ogihara T, Suzuki N: Evidence for endothelin-I release from resistance vessels of rats in response to hypoxia. Biochem Biophys Res Commun 1990, 169:973-977.

13. Xie H, Bevan JA: Oxidized low-density lipoprotein enhances myogenic tone in the rabbit posterior cerebral artery through the release of endothelin-I. Stroke 1999, 30:2423-2429.

14. Chow M, Dumont AS, Kassell NF: Endothelin receptor antagonists and cerebral vasospasm: an update. Neurosurgery 2002, 5 I:|333-|34|.

15. Lan C, Das D, Wloskowicz A, Vollrath B: Endothelin-I modulates hemoglobin-mediated signaling in cerebrovascular smooth muscle via RhoA/Rho kinase and protein kinase $\mathbf{C}$. Am J Physiol Heart Circ Physiol 2004, 286: HI 65-HI73.

16. Jinnouchi $\mathrm{K}$ : Mechanism of endothelin I production in the cochlea of rats. ORL J Otorhinolaryngol Relat Spec 200I, 63:6-II.

17. Scherer EQ, Wonneberger K, Wangemann P: Differential desensitization of $\mathrm{Ca}^{2+}$ mobilization and vasoconstriction by ETA receptors in the gerbil spiral modiolar artery. J MembrBiol 200I, I82: |83-19|.

18. Herzog M, Scherer EQ, Albrecht B, Rorabaugh B, Scofield MA, Wangemann P: CGRP Receptors in the Gerbil Spiral Modiolar Artery Mediate a Sustained Vasodilation via a Transient cAMP-mediated Ca2+-decrease. J Membr Biol 2002, I 89:225-236.

19. Wangemann P, Cohn ES, Gruber DD, Gratton MA: Ca2+-dependence and nifedipine-sensitivity of vascular tone and contractility in the isolated superfused spiral modiolar artery in vitro. Hear Res 1998, I I 8:90-100.

20. Goto K, Kasuya Y, Matsuki N, Takuwa Y, Kurihara H, Ishikawa T, Kimura S, Yanagisawa M, Masaki T: Endothelin activates the dihydropyridine-sensitive, voltage-dependent $\mathrm{Ca}^{2+}$ channel in vascular smooth muscle. Proc Natl Acad Sci USA 1989, 86:3915-3918.

21. Enoki T, Miwa S, Sakamoto A, Minowa T, Komuro T, Kobayashi S, Ninomiya $H$, Masaki T: Functional coupling of ETA receptor with $\mathrm{Ca}\left({ }^{2+}\right)$-permeable nonselective cation channel in mouse fibroblasts and rabbit aortic smooth-muscle cells. J Cardiovasc Pharmacol 1995, 26(Suppl 3):S258-S26I.

22. Guibert $C$, Beech DJ: Positive and negative coupling of the endothelin ETA receptor to $\mathrm{Ca}^{2+}$-permeable channels in rabbit cerebral cortex arterioles. I Physiol (Lond) 1999 5 | 4:843-856.

23. Uehata M, Ishizaki T, Satoh H, Ono T, Kawahara T, Morishita T, Tamakawa $\mathrm{H}$, Yamagami K, Inui J, Maekawa M, Narumiya S: Calcium sensitization of smooth muscle mediated by a Rho-associated protein kinase in hypertension. Nature 1997, 389:990-994.

24. Davies SP, Reddy H, Caivano M, Cohen P: Specificity and mechanism of action of some commonly used protein kinase inhibitors. Biochem / 2000, 35 I:95-105.

25. Ishizaki T, Uehata M, Tamechika I, Keel J, Nonomura K, Maekawa M, Narumiya S: Pharmacological properties of Y-27632, a specific inhibitor of rho- associated kinases. Mol Pharmacol 2000, 57:976-983

26. Shimokawa H, Seto M, Katsumata N, Amano M, Kozai T, Yamawaki T, Kuwata K, Kandabashi T, Egashira K, Ikegaki I, Asano T, Kaibuchi K, Takeshita A: Rho-kinase-mediated pathway induces enhanced myosin light chain phosphorylations in a swine model of coronary artery spasm. Cardiovasc Res 1999, 43:1029-1039.

27. Nakamura K, Nishimura J, Hirano K, Ibayashi S, Fujishima M, Kanaide $\mathrm{H}$ : Hydroxyfasudil, an active metabolite of fasudil hydrochloride, relaxes the rabbit basilar artery by disinhibition of myosin light chain phosphatase. J Cereb Blood Flow Metab 200I, $21: 876-885$

28. Kimura $K$, Ito $M$, Amano $M$, Chihara $K$, Fukata $Y$, Nakafuku M, Yamamori B, Feng J, Nakano T, Okawa K, Iwamatsu A, Kaibuchi K: Regulation of myosin phosphatase by Rho and Rho-associated kinase (Rho- kinase). Science 1996, 273:245-248.

29. Mukai Y, Shimokawa H, Matoba T, Kandabashi T, Satoh S, Hiroki J, Kaibuchi K, Takeshita A: Involvement of Rho-kinase in hypertensive vascular disease: a novel therapeutic target in hypertension. FASEB J 200I, I5:1062-1064.
30. Bonnevier J, Fassler R, Somlyo AP, Somlyo AV, Arner A: Modulation of $\mathrm{Ca}^{2+}$ Sensitivity by Cyclic Nucleotides in Smooth Muscle from Protein Kinase G-deficient Mice. J Biol Chem 2004, 279:5|46-5|5|.

3I. Ise S, Nishimura J, Hirano K, Kara N, Kanaide H: Theophylline attenuates $\mathrm{Ca}^{2+}$ sensitivity and modulates $\mathrm{BK}$ channels in porcine tracheal smooth muscle. $\mathrm{Br}$ J Pharmacol 2003, 140:939-947.

32. Lee H, Sohn SI, Jung DK, Cho YW, Lim JG, Yi SD, Lee SR, Sohn CH, Baloh RW: Sudden Deafness and Anterior Inferior Cerebellar Artery Infarction. Stroke 2002, 33:2807-28I2.

33. Shibuya M, Suzuki Y, Sugita K, Saito I, Sasaki T, Takakura K, Nagata I, Kikuchi H, Takemae T, Hidaka H: Effect of AT877 on cerebral vasospasm after aneurysmal subarachnoid hemorrhage. Results of a prospective placebo-controlled double-blind trial. J Neurosurg 1992, 76:57|-577.

\section{Pre-publication history}

The pre-publication history for this paper can be accessed here:

http://www.biomedcentral.com/1472-6815/5/10/prepub
Publish with Biomed Central and every scientist can read your work free of charge

"BioMed Central will be the most significant development for disseminating the results of biomedical research in our lifetime. "

Sir Paul Nurse, Cancer Research UK

Your research papers will be:

- available free of charge to the entire biomedical community

- peer reviewed and published immediately upon acceptance

- cited in PubMed and archived on PubMed Central

- yours - you keep the copyright
BioMedcentral 